\title{
Pengaruh Harga Dan Citra Merek Terhadap Minat Beli Wisatawan Domestik Di Pusat Oleh-Oleh Joger, Kuta, Bali
}

\author{
Risa Kariba Jambak ${ }^{\text {a1 }}$, I Made Sukana ${ }^{\text {a2 }}$ \\ ${ }^{1}$ risakariba@gmail.com, ${ }^{2}$ madesukana@unud.ac.id \\ a Program Studi Sarjana Destinasi Pariwisata, Fakultas Pariwisata Universitas Udayana, Jl. Dr. R. Goris, Denpasar, Bali 80232 Indonesia
}

\begin{abstract}
The development of business today is increasingly complex. Everyday people are involved in business activity such as purchasing of merits and stuffes. In this era of globalization, the business competition must be transparant and consistent in meeting the needs of consumers, beside they must also compete with competitors to maintain the image of their consumers. This also applies to the tourism industry. One of the tourism industries engaged in goods and services is the business center for souvenirs (shopping tourism). Several things that items to be considered as business are factors that can influence the buying interest of tourists at the center of souvenirs. This study aims to analyze the influence of price factors and brand image related to domestic tourist shopping interests at the Jogger souvenir center, Kuta, Bali.

This study uses multiple regression analysis methods with data sourced from observations, interviews, questionnaires, documentation and literature studies with non-probability sampling techniques as a method of determining to sample. Based on this research it could be concluded by the price factor and brand image has a significant influences on the buying interest of domestic tourists on Joger, Kuta, Bali.
\end{abstract}

\section{Keywords: Tourist Characteristics, Price, Brand Image, Purchase Interest, Joger Kuta.}

\section{PENDAHULUAN}

Ketika melakukan perjalanan wisata, tentunya wisatawan memiliki minat untuk membeli sesuatu yang khas dari daerah tersebut, seperti cenderamata atau souvernir, pakaian, dan makanan. Hal ini menyebabkan perkembangan bisnis pariwisata semakin menjalar dan semakin meningkat di setiap harinya. Pada perkembangan zaman yang modern seperti ini, berbagai jenis bisnis tentunya memiliki banyak pesaing, dan arena bersaing itu harus dilakukan secara transparan demi mempertahankan image atau citra dari tokonya terhadap konsumennya. Hal ini seperti bisnis dalam industri pariwisata. Menurut Armaji (dalam Yoeti, 1996) mengemukakan bahwa industri pariwisata adalah ringkasan dari segala bidang atau aspek pariwisata yang secara keseluruhan yang menghasilkan produk atau jasa dimana produk dan jasa tersebut akan dibutuhkan oleh wisatawan. Salah satu jenis industri pariwisata yang bergerak di bidang barang dan jasa adalah bisnis dalam wisata belanja seperti pusat oleh-oleh.

Pariwisata di Bali semakin hari semakin terkenal dan berkembang, tidak hanya dikenal oleh masyarakat Indonesia saja tetapi dari mancanegara pun mengenal Bali sebagai lokasi pariwisata yang besar. Potensi pembukaan usaha memang menjanjikan, dan hal ini membuat para investor tertarik untuk membuka usaha di Bali. Provinsi Bali merupakan salah satu daerah yang sektor pariwisatanya sudah termasuk kedalam pariwisata yang berkembang. Hal ini dapat dibuktikan dari berbagai daya tarik wisata di Bali yang telah memiliki kelengkapan baik di ketersediaan fasilitas maupun ketersediaan aksesnya.

Pusat perbelanjaan Oleh-Oleh Joger atau yang biasa disebut juga sebagai pabrik katakata unik dan menggelitik ini berlokasi di Jalan Raya Kuta yang lokasinya tidak begitu jauh dari lokasi Bandara Internasional Ngurah Rai. Joger merupakan pusat oleh-oleh yang di setiap harinya selalu dipenuhi oleh berbagai jenis wisatawan, salah satunya adalah wisatawan domestic yang berkunjung ke Bali dan mencari suatu souvenir yang menarik untuk dibawa ke daerah asalnya. Karena kuatnya unsur kata-kata dan sudah terkenalnya Joger, sehingga hal tersebut menjadikan Pusat Oleh-Oleh Joger menjadi salah satu minat belanja bagi wisatawan. Oleh karenanya maka peneliti melakukan penelitian mengenai pengaruh harga dan citra merek terhadap minat belanja wisatawan domestik pad Pusat Oleh-Oleh Joger, Kuta, Bali. 


\section{TINJAUAN PUSTAKA}

Penelitian sebelumnya dilakukan agar mengetahui perbedaan antar penelitian, sehingga hal ini penting maka dari itu dilakukan perbandingan terhadap penelitian terdahulu dengan penelitian yang dilakukan sekarang berdasarkan dari fokus penelitian dan lokasi penelitian, hal ini dilakukan agar tidak adanya penelitian berganda serta untuk mengetahui keunggulan dari tiap-tiap penelitian.

Penelitian yang pertama dilakukan oleh Yulianti (2014), pada penelitian ini memiliki perbedaan yaitu di penelitian pertama menitik beratkan kepada pengaruh citra toko terhadap kepuasan pelanggan, sedangkan pada penelitian yang sekarang kepada pengaruh dari harga dan citra merek terhadap minat beli wisatawan.

Penelitian yang selanjutnya dilakukan oleh Subrata, dkk (2015), pada penelitian ini memiliki perbedaan yaitu pada penelitian yang kedua menetapkan lokasi penelitian di Pasar Seni Tradisional Gianyar, sedangkan pada penelitian yang sekarang menggunakan lokasi di Pusat Oleh-Oleh Joger, Kuta, Bali.

Dari pengkajian penelitian yang telah ada, tidak ditemukan adanya hasil penelitian dan lokasi penelitian yang sama dengan penelitian yang sekarang. Maka dari itu, penelitian yang telah ada digunakan sebagai bahan referensi untuk memperkaya penelitian ini.

Adapun konsep yang digunakan pada penelitian ini adalah ; Konsep pengunjung dan Karakteristiknya oleh Seaton dan Bennet (1996) ; Konsep Minat Beli oleh Ferdinand (2002) ; Konsep Citra Merek oleh Kotler dan Keller (2009) serta Low dan Lamb (2001) ; Konsep Harga oleh Lamb (2001).

\section{III.METODE PENELITIAN}

Penelitian ini dilakukan di Pusat Oleh-Oleh Joger, Kuta, Bali. Joger berada pada lokasi yang terbilang strategis karena berada di area terbuka, sehingga tidak untuk menemukan lokasi dari pusat oleh-oleh ini.

Penelitian ini menggunakan data kuantitatif berupa hasil analisis dari regresi berganda kemudian diolah dengan menggunakan program penghitungan SPSS. Adapun data kualitatif yang digunakan dala penelitian ini berupa deskripsi hasil dari uji hipotesis dan data berupa hasil dari persentase yang diperoleh dari hasil jawaban responden. Sumber data primer yaitu berupa hasil observasi melalui suatu kondisi yang dilihat pada lokasi penelitian, serta penyebaran kuesioner yang di lakukan di lokasi penelitian yaitu pusat oleh-oleh Joger. Adapun data sekunder yang digunakan yaitu berupa data yang dikumpulkan dari jurnal, skripsi, dan hasil dokumentasi yang di dapat di lokasi penelitian.

Dalam penentuan sampel dingunakan teknik non probability sampling yaitu memilih responden secara sengaja dengan pertimbangan bahwa responden tersebut dapat memberikan informasi serta data yang diperlukan (Sugiyono, 2004). Sehingga dengan menggunakan margin of error (Moe) sebesar $10 \%$ atau 0,1 maka jumlah minimal dari responden yang dibutuhkan adalah 96 responden $\left(1,96^{2} / 4(0,1)^{2}\right)$ yang dimana 1,96 berupa tingkat kontribusi normal ada taraf yang signifikan. Setelah didapat jumlah minimal dari responden sebanyak 96 responden, kemudian dilakukan pembulatan sehingga responden yang diperlukan dalam penelitian ini adalah sebanyak 100 responden.

Teknik pengumpulan data dilakukan dengan cara observasi langsung ke lokasi penelitian untuk mengetahui bagaimana kondisi wisatawan serta karakteristik dari wisatawan yang datang ke Joger, kuesioner yang dilakukan untuk mengetahui tanggapan atau opini dari wisatawan terhadap fokus penelitian yang dimana hasil dari data kuesioner akan diolah menggunakan program penghitungan SPSS, serta persentase karakteristik dari wisatawan yang datang ke Joger, dan dokumentasi dilakukan sebagai hasil dari suasana Joger berupa gambar lokasi atau foto dari penyebaran kuesioner.

\section{HASIL DAN PEMBAHASAN \\ 4.1 Karakteristik Responden}

Karakteristik wisatawan yang datang mengunjungi Pusat Oleh-Oleh Joger didominasi oleh wisatawan perempuan yaitu dengan persentase sebesar $60 \%$, sedangkan $40 \%$ lainnya adalah laki-laki. Adapun cakupan usia yang datang ke Pusat Oleh-Oleh Joger didominasi oleh kalangan remaja dengan rentang usia sekitar 15 tahun sampai dengan 20 tahun dengan persentase sebesar 49\%, selanjutnya diikuti oleh usia 21 tahun sampai 
dengan 30 tahun dengan persentase sebesar $48 \%$, kemudian pada usia 31 tahun sampai dengan 40 tahun sebesar $2 \%$, dan yang paling sedikit atau jarang adalah responden dengan usia 41 tahun sampai dengan 50 tahun dengan persentase paling sedikit yaitu sebesar $1 \%$.

\subsection{Regresi Linear Berganda}

Dari data yang telah diperoleh melalui hasil analisis dengna SPSS, maka didapat hasil dari regresi linear berganda dengan rumus yang dapat digunakan adalah sebagai berikut:

$$
Y=-0.1370+0.281 X 1+0.598 \times 2+e
$$

Melalui persamaan tersebut diatas, maka dapat didefenisikan sebagai berikut :

1. $\quad \alpha$ (konstanta) memiliki nilai -1.370 yang berarti bahwa semua nilai variabel bebas dalam hal ini adalah harga dan citra merek tidak memiliki nilai 0 (nol), maka nilai dari variabel minat beli adalah sebesar -1.370. Atau dalam kata lain bahwa garis dari regresi tidak akan memotong sumbu $Y$.

2. $\quad \beta 1$ memiliki nilai sebesar 0.281 yang berarti apabila variabel harga naik sebesar 1 (satu) satuan dan nilai dari variabel lain tetap stabil (konstan) maka variabel dari minat beli pun akan ikut naik sebesar 0.281 satuan.

3. $\quad \beta 2$ memiliki nilai sebesar 0.598 yang berarti apabila variabel citra merek naik sebesar 1 (satu) satuan dan nilai dari variabel lain tetap stabil (konstan) maka variabel dari minat beli pun akan ikut naik sebanyak 0.598 satuan.

Dari data variabel diatas dapat dikatakan bahwa semakin meningkatnya nilai harga maka nilai dari minat beli wisatawan pun akan meningkat. Akan tetapi dari data yang diperoleh hanya menunjukkan nilai sebanyak 0.281 yang artinya pengaruh yang disebabkan tidak begitu terlihat atau tidak terlalu banyak

Dari data variabel citra merek dapat dikatakan bahwa semakin meningkatnya nilai citra merek dari Joger, maka nilai variabel dari minat beli pun akan meningkat. Dengan hasil nilai yang diperoleh yaitu sebanyak 0.598 yang artinya bahwa citra merek memiliki pengaruh yang dominan terhadap minat beli wisatawan.

\subsection{Uji Koefisien Determinasi Berganda}

$\left(\mathbf{R}^{2}\right)$

Berdasarkan hasil yang diperoleh melalui analisis dengan SPSS pada koefisien determinasi berganda $\left(R^{2}\right)$ maka nilai dari $R$ yang diperoleh adalah 0.818. Dari nilai yang diperoleh tersebut, maka selanjutnya nilai dari persentase $\mathrm{R}^{2}$ akan dihitung dengan menggunakan rumus ;

\section{$\mathrm{KD}=\mathrm{R} 2 \times 100 \%$ \\ Dimana R sebanyak 0.818, maka $(0.818)^{2} \times 100 \%$, diperoleh hasil sebanyak $67 \%$}

Nilai dari koefisien determinasi berganda (R2) diperoleh sebanyak $67 \%$ yang berarti bahwa nilai harga dan citra merek memiliki kontribusi yang signifikan terhadap minat beli wisatawan domestik di Pusat Oleh-Oleh Joger, Kuta-Bali yaitu sebesar 67\%. Sedangkan sisanya sebanyak $33 \%$ adalah kontribusi dari pengaruh luar atau asing yang dimana variabel-variabelnya tidak dicantumkan ke dalam model penelitian ini.

\subsection{Uji F (Uji Simultan)}

Hipotesis Uji ;

1. Apabila $\mathrm{H} 0 \rightarrow$ bYX1 $=0$ dan $\mathrm{H} 0 \rightarrow$ bYX2 $=0$, maka variabel harga tidak memiliki pengaruh yang signifikan terhadap minat beli. Begitu pula dengan citra merek yang tidak memiliki engaruh yang signifikan terhadap minat beli.

2. Apabila $\mathrm{H} 0 \rightarrow$ bYX1 $\neq 0$ dan $\mathrm{H} 0 \rightarrow$ bYX2 $\neq 0$, maka variabel harga emiliki pengaruh yang signifikan terhadap minat beli, begitu pula dengan citra merek yang memiliki pengaruh yang signifikan terhadap minat beli.

Pada pengujian simultan di kedudukan yang signifikan " $\alpha$ " adalah sebanyak 5\%.

Dari hasil perhitungan menggunakan SPSS, maka diperoleh hasil dari $F_{\text {hitung }}$ adalah sebanyak 98.333. Dimana hasil tersebut akan dipertimbangkan dengan hasil $\mathrm{F}$, dengan $\alpha=$ $5 \% ; \mathrm{df}_{1}=\mathrm{k}=2$, dan $\mathrm{df}_{2}=\mathrm{n}-\mathrm{k}-1=100-2-1$ $=97$, maka hasil dari $\mathrm{F}_{\text {tabel }}$ adalah sebanyak 18 . Karena $\mathrm{F}_{\text {hitung }}$ lebih besar dibandingkan nilai $\mathrm{F}_{\text {tabel }}(98.333$ > 18), maka H0 ditolak dan H1 diterima, dengan arti bahwa variabel harga dan variabel citra merek memiliki pengaruh yang signifikan secara parsial dengan variabel minat beli. 


\subsection{Uji Parsial}

Berdasarkan hasil uji yang dilakukan secara parsial guna untuk menguji antara variabel yang bebas dengan variabel yang terikat, maka hasil pengujian $t$ yang diperoleh adalah ;

\section{Pengaruh Harga Terhadap Minat Beli Wisatawan Domestik di Pusat Oleh- Oleh Joger, Kuta-Bali}

Dari kriteria pengujian yang dipaparkan bahwa terlihat nilai dari thitung pada variabel harga berada di daerah penolakan dimana 2.812 lebih besar dari pada 2.000 dan dengan nilai signifikansi sebesar 0.006 dimana nilai tersebut berada dibawah atau lebih kecil dari nilai signifikansi yaitu sebesar 0,5. Hal ini menjelaskan bahwa nilai dari variabel harga memiliki pengaruh yang positif dan signifikan terhadap terhadap minat beli wisatawan domestik di Pusat Oleh-Oleh Joger, Kuta-Bali.

Lamb (2001) menyatakan bahwa harga merupakan hal yang akan diserahkan dalam suatu pertukaran guna mendapatkan suatu barang atau jasa. Dalam hal ini dapat dikatakan bahwa harga yang dibayar oleh wisatawan atau konsumen tidak hanya berupa barang, tetapi jasa atau pelayanan pun akan diterima oleh konsumen.

Untuk itu apabila Joger memiliki kualitas barang dan pelayanan yang bagus maka harga yang diberikan kepada konsumen akan memberikan hasil yang positif dalam bentuk minat beli eksporatif wisatawan kepada Joger, sehingga wisatawan tidak akan berfikir berulang dalam menentukan minat belinya kepada Joger (Ferdinand, 2002)

\section{Pengaruh Citra Merek Terhadap Minat Beli Wisatawan Domestik di Pusat Oleh-Oleh Joger, Kuta-Bali}

Dari kriteria pengujian yang dipaparkan bahwa terlihat nilai dari thitung pada variabel citra merek berada pada daerah penolakan dimana 9.260 lebih besar dari pada 2.000 dan dengan nilai signifikansi sebesar 0.000 dimana nilai tersebut dibawah atau lebih kecil dari nilai signifikansi yaitu sebesar 0,5. Hal ini menjelaskan bahwa citra merek memiliki pengaruh yang positif dan signifikan terhadap minat beli wisatawan domestik di Pusat OlehOleh Joger, Kuta-Bali.

Citra merek merupakan alat yang dimiliki oleh suatu perusahaan yang dapat meyakinkan konsumen dalam memilih suatu produk atau jasa (Kotler dan Keller, 2009). Citra merek bukan hanya merupakan suatu atribut tetapi citra merek juga melambangkan dari suatu nilai, budaya, serta kepribadian dari perusahaan tersebut.

Joger memiliki Citra Merek yang positif terhadap minat beli wisatawan domestik, hal ini disebabkan karena Joger memiliki ciri khas tersendiri dalam mewakili nilai, budaya, serta kepribadian dari Bali yang dituangkan melalui kata-kata unik. Oleh sebab itu banyak wisatawan yang tertarik dengan Joger, dan dapat dikatakan bahwa citra merek tersebut dapat menarik wisatawan domestik dalam menumbuhkan minat belinya kepada Pusat Oleh-Oleh Joger, Kuta-Bali.

\section{PENUTUP}

\subsection{Kesimpulan}

1. Bahwa wisatawan yang datang ke Pusat Oleh-Oleh Joger, Kuta-Bali didominasi oleh wisatawan wanita dengan persentase sebanyak $60 \%$ dengan rentang usia tergolong remaja karena memiliki usia sekita 15 tahun sampai dengan 20 tahun yaitu sebanyak 49\%.

2. Bahwa variabel harga dan variabel citra merek memiliki pengaruh yang positif serta signifikan terhadap variabel minat beli wisatawan domestik di Pusat OlehOleh Joger, Kuta-Bali.

\subsection{Saran}

1. Diharapkan pemilik dari pusat perbelanjaan oleh-oleh Joger lebih terbuka terhadap mahasiswa yang ingin melakukan penelitian terhadap usaha pariwisata yang dimilikinya. Sehingga mahasiswa yang diberi tugas penelitian tersebut memiliki kesempatan dalam memperoleh data yang lebih banyak serta mendalam lagi, guna untuk melengkapi laporan data penelitian tersebut.

2. Pusat perbelanjaan oleh-oleh Joger harus lebih meningkatkan kualitas dari pelayanan dan desain produk yang dijual, sehingga dapat terus menarik minat beli dari wisatawan.

\section{DAFTAR PUSTAKA}

Bennet, JA. 1996. Introduction To Travel And Tourism Marketing. Landsowne. 
Ferdinand. 2002. Pengembangan Minat Beli Merek Ekstensi. Semarang.

Kotler, dkk. 2009. Manajemen Pemasaran. Jilid I, Indeks. Jakarta.

Lamb, dkk. 2001. An Expanded Price Or Brand Effect Model : A Demonstration Of Heterogeneity In Global Consumption.

Subrata, I gede. 2015. Analisis Faktor-Faktor Yang Mempengaruhi Minat Belanja Wisatawan Domestic Ke Pasar Tradisional Gianyar. STP Nusa Dua, Bali.

Sugiyono. 2009. Metodologi Penelitian Kuantitatif dan Kualitatif. Alfabeta. Bandung.

Yoeti, Oka. 1996. Pengantar Ilmu Pariwisata. Angkasa. Bandung.

Yulianti, Dhian Ni Made. 2014. Pengaruh sitra toko terhdap kepuasan pelanggan dan minat beli ulang pada circle $k$ di Denpasar. Universitas udayana. 